\title{
Histone Lysine Methylation in TGF- $\beta 1$ Mediated p21 Gene Expression in Rat Mesangial Cells
}

\author{
Qiaoyan Guo, ${ }^{1}$ Xiaoxia Li, ${ }^{1}$ Hongbo Han, ${ }^{2}$ Chaoyuan Li, ${ }^{1}$ Shujun Liu, \\ Wenhui Gao, ${ }^{3}$ and Guangdong Sun ${ }^{1}$ \\ ${ }^{1}$ Department of Nephrology, 2nd Hospital of Jilin University, Changchun 130041, China \\ ${ }^{2}$ Department of Endocrinology, 208th Hospital of Chinese PLA, Changchun 130062, China \\ ${ }^{3}$ Department of Neonatology, 2nd Hospital of Jilin University, Changchun 130041, China
}

Correspondence should be addressed to Guangdong Sun; sungd@jlu.edu.cn

Received 13 February 2016; Accepted 11 April 2016

Academic Editor: Yujungeorge Zheng

Copyright (C) 2016 Qiaoyan Guo et al. This is an open access article distributed under the Creative Commons Attribution License, which permits unrestricted use, distribution, and reproduction in any medium, provided the original work is properly cited.

Transforming growth factor betal- (TGF- $\beta 1$-) induced p21-dependent mesangial cell (MC) hypertrophy plays a key role in the pathogenesis of chronic renal diseases including diabetic nephropathy (DN). Increasing evidence demonstrated the role of posttranscriptional modifications (PTMs) in the event; however, the precise regulatory mechanism of histone lysine methylation remains largely unknown. Here, we examined the roles of both histone $\mathrm{H} 3$ lysine 4 and lysine 9 methylations (H3K4me/H3K9me) in TGF- $\beta 1$ induced p21 gene expression in rat mesangial cells (RMCs). Our results indicated that TGF- $\beta 1$ upregulated the expression of p21 gene in RMCs, which was positively correlated with the increased chromatin marks associated with active genes (H3K4me1/H3K4me2/H3K4me3) and negatively correlated with the decreased levels of repressive marks (H3K9me2/H3K9me3) at p21 gene promoter. TGF- $\beta 1$ also elevated the recruitment of the H3K4 methyltransferase (HMT) SET7/9 to the p21 gene promoter. SET7/9 gene silencing with small interfering RNAs (siRNAs) significantly abolished the TGF- $\beta 1$ induced p21 gene expression. Taken together, these results reveal the key role of histone H3Kme in TGF- $\beta 1$ mediated p21 gene expression in RMC, partly through HMT SET7/9 occupancy, suggesting H3Kme and SET7/9 may be potential renoprotective agents in managing chronic renal diseases.

\section{Introduction}

Glomerular diseases are the leading causes of chronic kidney disease (CKD) and end-stage renal disease (ESRD) worldwide; several renal cells including mesangial cells (MC), podocytes, epithelial cells, and endothelial cells are involved in the pathogenesis. MCs' response to injury includes apoptosis, proliferation, and hypertrophy, and MC hypertrophy is a hallmark of IgA nephropathy (IgAN), membranoprolifrative glomerulonephritis (MPGN), lupus nephritis (LN), and DN [1-4]. A lot of studies have shown the key role of cyclindependent kinase inhibitor (CDKI) such as p21 and P27 in MC hypertrophy [5-7]; attenuation of $\mathrm{p} 21$ by antisense oligodeoxynucleotide (ODN) could decrease MC hypertrophy induced by hyperglycemia and IGF-1 [8]; as a result diabetic p21 -/- mice did not develop glomerular hypertrophy; all data suggest p21 may be necessary for glomerular hypertrophy mediated by TGF- $\beta 1$ in chronic renal diseases including DN $[5,9]$.
TGF- $\beta 1$ has been implicated in initial glomerular hypertrophy and subsequent accumulation of extracellular matrix (ECM) in CKD, and MC hypertrophy has been recognized as the fundamental change in the pathogenesis $[10,11]$. Renal cells are a rich source of TGF- $\beta 1$. Diverse factors such as high glucose, Ang II, and AGE could stimulate the production of TGF- $\beta 1$ in MC [12-14]; treatment of diabetic mice with a neutralizing anti-TGF- $\beta$ antibody could completely prevent diabetic glomerular hypertrophy [15]. TGF- $\beta 1$ induced MC hypertrophy may be mediated by PKC-independent mechanisms [16], regulation of IP3Rs [15], AGE-RAGE-mediated reactive oxygen species (ROS) generation [14], a feedback loop between deptor downregulation and TORC1/2 activation instilled by Smad3 [17], or PI3K-Akt activation through FOG2 downregulation by miR-200b/c [18]. Evidences are emerging from in vivo and in vitro studies that $\mathrm{p} 21$ is required for MC or glomerular hypertrophy induced by TGF- $\beta 1[5,9$, $19-22]$, but how TGF- $\beta 1$ regulates p21 is not fully clear. 
TABLE 1: Sequences of RT-QPCR and ChIP-QPCR primers.

\begin{tabular}{llll}
\hline Primer & Forward primer & Reverse primer & Annealing temprature \\
\hline cDNA primers & & & 58 \\
rp21 & TGTTCCACACAGGAGCAAAG & AACACGCTCCCAGACGTAGT & 58 \\
rCypA & TATCTGCACTGCCAAGACTGAGTG & CTTCTTGCTGGTCTTGCCATTCC & 62 \\
r $\beta$-actin & CTGCCCTGGCTCCTAGCAC & cggacGCAGCTCAGTAACAGTCcG & \\
ChIP primers & & & 58 \\
rp21pro & CGCCCCTTTCTAGCTGTCTG & CAGATCTGCGGTCTTATAGCATC & 58 \\
rCypApro & TATCTGCACTGCCAAGACTGAGTG & CTTCTTGCTGGTCTTGCCATTCC & \\
\hline
\end{tabular}

Epigenetic modifications have been increasingly recognized as novel, important contributors to gene regulation in multiple diseases. Epigenetic mechanisms include DNA methylation, posttranslational modification (PTM), and miRNA regulation. The most abundant PTMs are the phosphorylation, acetylation, methylation, and ubiquitylation at amino-terminal tails of lysines on histone $\mathrm{H} 3$ or H4. Gene activation is usually associated with lysine acetylation on $\mathrm{H} 3$ and $\mathrm{H} 4$ residues (HKAc), methylation of $\mathrm{H} 3$ lysine 4 (H3K4me), trimethylation of $\mathrm{H} 3$ lysine 79 (H3K79me3), and trimethylation of $\mathrm{H} 3$ lysine 36 ( $\mathrm{H} 3 \mathrm{~K} 36 \mathrm{me} 3)$, whereas di- or trimethylation of $\mathrm{H} 3$ lysine 9 (H3K9me2/3) and trimethylation of $\mathrm{H} 3$ lysine 27 ( $\mathrm{H} 3 \mathrm{~K} 27 \mathrm{me} 3)$ are linked to gene repression; there is also crosstalk between active and repressive modifications in gene regulation. The enhanced level of TGF$\beta 1$-mediated p 21 mRNA in RMCs has been reported to be associated with H3K9/14Ac levels [22], and TGF- $\beta 1$ induced ECM associated genes upregulation was associated with enhanced levels of $\mathrm{H} 3 \mathrm{~K} 4 \mathrm{mel} / 2 / 3$ and decreased $\mathrm{H} 3 \mathrm{~K} 9 \mathrm{me} 2 / 3$ levels [23]; there is no report on the role of histone methylation in TGF- $\beta 1$-induced p 21 gene expression in RMC. SET7/9 has been identified as a histone lysine methyltransferase (HMT), generating monomethylation of histone $\mathrm{H} 3$ lysine 4 (H3K4mel); several reports have found that SET7/9 and the associated $\mathrm{H} 3 \mathrm{~K} 4 \mathrm{mel}$ involved in profibrotic and inflammatory genes regulation [23-26]. TGF- $\beta 1$ stimulation upregulated SET7/9 expression and SET7/9 recruitment at ECM associated genes promoters, and knockdown of SET7/9 with siRNAs could partly abolish TGF- $\beta 1$ induced ECM associated genes upregulation. However, the roles of active and repressive histone $\mathrm{H} 3$ lysine methylation ( $\mathrm{H} 3 \mathrm{Kme}$ ) and key HMT SET7/9 in the regulation of TGF- $\beta 1$ mediated p21 gene expression in RMCs are not clear.

In this report, we demonstrate that TGF- $\beta 1$ induces decreased levels of $\mathrm{H} 3 \mathrm{~K} 9 \mathrm{me}$ and the enrichment of $\mathrm{H} 3 \mathrm{~K} 4 \mathrm{me}$ at $\mathrm{p} 21$ promoter in RMCs, at the same time we elucidate that HMT SET7/9 plays a key role in TGF- $\beta 1$ mediated p 21 expression. These data demonstrate a novel epigenetic mechanism of TGF- $\beta 1$ induced $\mathrm{p} 21$ gene expression leading to $\mathrm{MC}$ hypertrophy, the characteristic of chronic renal diseases.

\section{Methods}

2.1. Cell Culture and Stimulation. Primary RMCs were obtained by explant culture of renal glomeruli isolated from Sprague-Dawley male rats (160-180 g) as described [23] with the allowance of the Ethics Committee on the Care and Use of Laboratory Animals of the Second Hospital of Jilin University (Changchun, China). RMCs were maintained in RPMI 1640 medium. The subsequent experiments were performed with RMCs from passages 6-10. RMCs were serum depleted in $0.2 \%$ BSA medium for $24 \mathrm{~h}$ prior to stimulation. RMCs were treated with $10 \mathrm{ng} / \mathrm{mL}$ Recombinant Human TGF- $\beta 1$ (240$\mathrm{B}, \mathrm{R} \& \mathrm{D}$ systems, Minneapolis, $\mathrm{MN}$ ) as indicated time, while control groups were treated with the vehicle.

2.2. Transfections of SET7/9 Small Interfering RNA (siRNA) into RMC. SET7/9 ON-TARGETplus siRNA (J-059399(0912))(siSET7/9) was from Thermo Scientific; and Silencer ${ }^{\circledR}$ Negative Control \#1 siRNA (AM4611)(siNeg) was from Ambion, Inc. Transfection of siRNAs to RMC was performed as described previously [23]. About $24 \mathrm{~h}$ after transfection, RMCs were depleted with serum-free RPMI 1640 medium containing $0.2 \% \mathrm{BSA}$ for $24 \mathrm{~h}$, then stimulated in the presence or absence of TGF- $\beta 1(10 \mathrm{ng} / \mathrm{mL})$ for $6 \mathrm{~h}$, and processed the detection for RNA levels by RT-QPCR.

2.3. RNA Isolation and RT-QPCR Analysis. Total RNA was extracted from RMCs using TRIzol reagent (Invitrogen, Carlsbad, CA, USA) according to the manufacturer's instructions; the RNA concentration was determined with the sample dissolved in diethylpyrocarbonate-treated water. Isolated RNA $(2 \mu \mathrm{g})$ was used in reverse transcription using TagMan Reverse Transcription Kit (Applied Biosystems Inc., Foster City, CA, USA) according to the manufacturer's protocol. The synthesized cDNA $(3 \mu \mathrm{L})$ was used for quantitative real-time PCR (QPCR) amplication. The specific primers were synthesized by Shanghai Invitrogen Biotechnology Co., Ltd. (listed in Table 1). QPCRs were performed with SYBR-green reagent (Life technologies, UK) in triplicate in a final volume of $20 \mu \mathrm{L}$ with ABI 7300 real-time PCR thermal cycler. Dissociation curves were run to detect nonspecific amplification and confirm single product was amplified in each reaction. The comparative cycle time $(\mathrm{Ct})$ method was applied to determine fold differences between samples, with the values normalized with internal control $\beta$-actin gene by $2^{-\Delta \Delta \mathrm{Ct}}$ method.

2.4. Western Blot Analysis. Proteins were extracted from RMCs samples and were homogenized in RIPA buffer (150 mM NaCl, 50 mM Tris-HCl, 1\% NP-40, 0.5\% sodium deoxycholate, and $0.1 \%$ SDS) plus protease and phosphatase inhibitors mixture. Equal amounts of protein samples $(30 \mu \mathrm{g})$ 
were separated by $10 \%$ SDS-PAGE gels and transferred to PVDF membranes. The membranes were blocked with 5\% milk for $1 \mathrm{~h}$ at room temperature. The immunoblotting was performed with primary antibody against p21 (MA1-91045, Thermo; $1: 1000)$ and incubated overnight at $4^{\circ} \mathrm{C}$. Proteins were detected with Chemiluminescence method. The blots were stripped and then reprobed with an antibody against $\beta$-actin (A5441, Sigma Aldrich, St. Louis, MO; 1:100000) as a load control. The densitometric analysis was performed using ImagJ (Wayne Rasband, National Institutes of Health, Bethesda, MD).

2.5. Chromatin Immunoprecipitation (ChIP) Assays. RMCs were treated with TGF- $\beta 1$ for $24 \mathrm{~h}$ and then cross-linked with $1 \%$ formaldehyde for $10 \mathrm{~min}$ at $37^{\circ} \mathrm{C}$, washed twice with cold PBS supplemented with protease inhibitors, and lysed as described previously [23]. Cell lysates were sonicated and diluted. Immunoprecipitation was performed overnight at $4^{\circ} \mathrm{C}$ with antibodies to methylated histones (H3K4mel (ab8895), H3K4me2 (ab32356), H3K4me3 (ab8580), H3K9me2 (ab1220), and H3K9me3 (ab8898); Abcam, Cambridge, MA), SET7/9 (11209, Sino Biological Inc), or IgG (antibody control). Immune complexes were obtained using protein $\mathrm{A} / \mathrm{G}$ beads and washed to remove nonspecific binding; bound proteins were eluted and ChIP-enriched DNA was collected by phenol and chloroform extraction. Antibody-enriched ChIP DNA and input DNA samples were analyzed by real-time PCR with indicated primers within p21 and control cyclophilin A (CypA) promoters (See Figure 2(a) and Table 1). All reactions were carried out in triplicate in a final volume of $20 \mu \mathrm{L}$. Data were analyzed with the $2^{-\Delta \Delta C t}$ method and normalized to input samples. Results were expressed as fold over control.

2.6. Statistical Analysis. Values were expressed as mean \pm SEM of multiple experiments. Differences between groups were assessed by Paired Student's $t$-tests or ANOVA with Dunnet's posttests. Statistical tests were performed using the GraphPad Prism 5.0 software. $P<0.05$ was considered to be statistically significance.

\section{Results}

3.1. TGF- $\beta 1$ Increases $p 21$ Gene Expression, While Reciprocally Inhibitory H3K9me Levels Are Downregulated at Its Promoter in RMC. Firstly we examined p21 gene expression in RMC in the presence or absence of TGF- $\beta 1(10 \mathrm{ng} / \mathrm{mL})$ for different time through RT-QPCR and western blot, and whether TGF$\beta 1$ induced $\mathrm{p} 21$ expression was associated with the changes in the repressive epigenetic marks $\mathrm{H} 3 \mathrm{~K} 9 \mathrm{me} 2$ and $\mathrm{H} 3 \mathrm{~K} 9 \mathrm{me} 3$ at its promoter. Serum depleted RMC was treated with or without TGF- $\beta 1$ for $6 \mathrm{~h}$, and p21 gene expression level was determined by RT-QPCR. p21 mRNA level was significantly increased in the presence of TGF- $\beta 1$ compared with control, while there was no difference in the housekeeping gene CypA between the two groups (Figure 1(a)). Western blot analysis showed that p21 protein level (Figure 1(b)) was also similarly increased in the presence of TGF- $\beta 1$ for $24 \mathrm{~h}$. These results suggested that TGF- $\beta 1$ can increase the expression of $\mathrm{p} 21$ gene in RMC as expected.

Next we examined the methylation status of $\mathrm{H} 3 \mathrm{~K} 9$ using ChIP assays with specific antibodies of H3K9me2 and H3K9me3. ChIP-enriched DNA samples were analyzed by QPCR using primers spanning Smad binding element (SBE) in the proximal region of the p21 promoter (Figure 2(a)). Levels of both H3K9me2 and H3K9me3 (Figure 2(b)) at p21 promoter were significantly decreased in RMC in the presence of TGF- $\beta 1$ for $24 \mathrm{~h}$ compared with the absence of TGF- $\beta 1$ (control, ctrl). In contrast, there was no significant difference at CypA promoter between two groups. These results suggested that TGF- $\beta 1$-induced p 21 expression may be due, at least partly, to the loss of inhibitory histone lysine methylation at its promoter.

3.2. TGF- $\beta 1$ Increases H3K4me Levels at the p21 Promoter. It has been recognized that specific posttranslational modifications of histones such as acetylation or methylation were associated with the activation of specific genes. We next investigated whether TGF- $\beta 1$ could influence H3K4me levels at the gene promoter of p21, the epigenetic "active" marks, using ChIP assays with $\mathrm{H} 3 \mathrm{~K} 4 \mathrm{mel}, \mathrm{H} 3 \mathrm{~K} 4 \mathrm{me} 2$, and H3K4me3 antibodies. As shown in Figure 3, $24 \mathrm{~h}$ TGF- $\beta 1$ treatment significantly enhanced $\mathrm{H} 3 \mathrm{~K} 4 \mathrm{me} 1, \mathrm{H} 3 \mathrm{~K} 4 \mathrm{me} 2$, and $\mathrm{H} 3 \mathrm{~K} 4 \mathrm{me} 3$ levels at the p21 promoter in RMC to different extent, and these increases in $\mathrm{H} 3 \mathrm{~K} 4 \mathrm{mel} / 2 / 3$ levels at p21 promoter are consistent with the upregulated expression of p21 gene after TGF- $\beta 1$ stimulation. On the other hand, there were no significant differences in these marks at the CypA promoter, confirming the specificity. These results indicated that increased $\mathrm{H} 3 \mathrm{~K} 4$ methylation levels might be involved in TGF- $\beta 1$ induced p21 gene upregulation in RMC.

3.3. TGF- $\beta 1$ Increases SET7/9 Recruitment to $p 21$ Gene Promoter. The HMT SET7/9 has been well characterized in gene regulation $[23,25-28]$. In previous study, TGF- $\beta 1$ has been proven to be a contributor to increase SET7/9 gene expression as well as SET7/9 occupancy to the promoters of ECM associated genes (Coll $\alpha 1$, CTGF, and PAI-1) [23]. Here, we investigated whether TGF- $\beta 1$ alters SET7/9 occupancy on the $\mathrm{p} 21$ promoter using ChIP assays with SET7/9 antibody. As shown in Figure 4(a), SET7/9 recruitment was significantly increased at $\mathrm{p} 21$ promoter in the presence of TGF- $\beta 1$ for $24 \mathrm{~h}$ compared with TGF- $\beta 1$ absent group (ctrl), and there was no significant difference at the CypA promoter in the TGF$\beta 1$ presence and absence groups. The SET7/9 recruitment pattern suggested an association with the increased $\mathrm{H} 3 \mathrm{~K} 4 \mathrm{mel}$ level induced by TGF- $\beta 1$ (Figure 3), indicating a key function of SET7/9 in TGF- $\beta 1$-mediated upregulation of H3K4me1 level in the induction of the p21 gene.

\subsection{Knockdown of SET7/9 Partly Abolished TGF- $\beta 1-I n d u c e d$} p21 Gene Expression. In the previous study we have shown that knockdown of SET7/9 by siSET7/9 could partly abolish TGF- $\beta 1$-induced ECM associated genes expression. To better understand the role of SET7/9 in TGF- $\beta 1$ induced $\mathrm{p} 21$ 

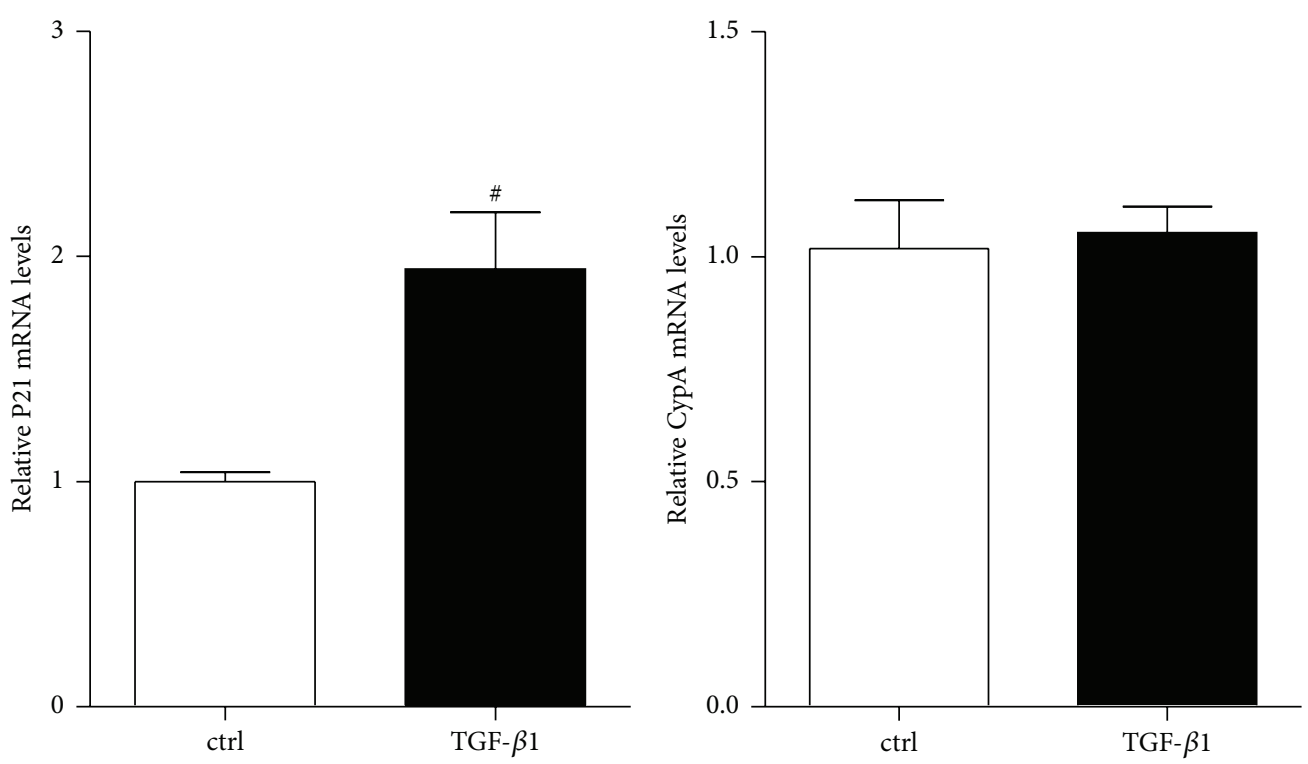

(a)
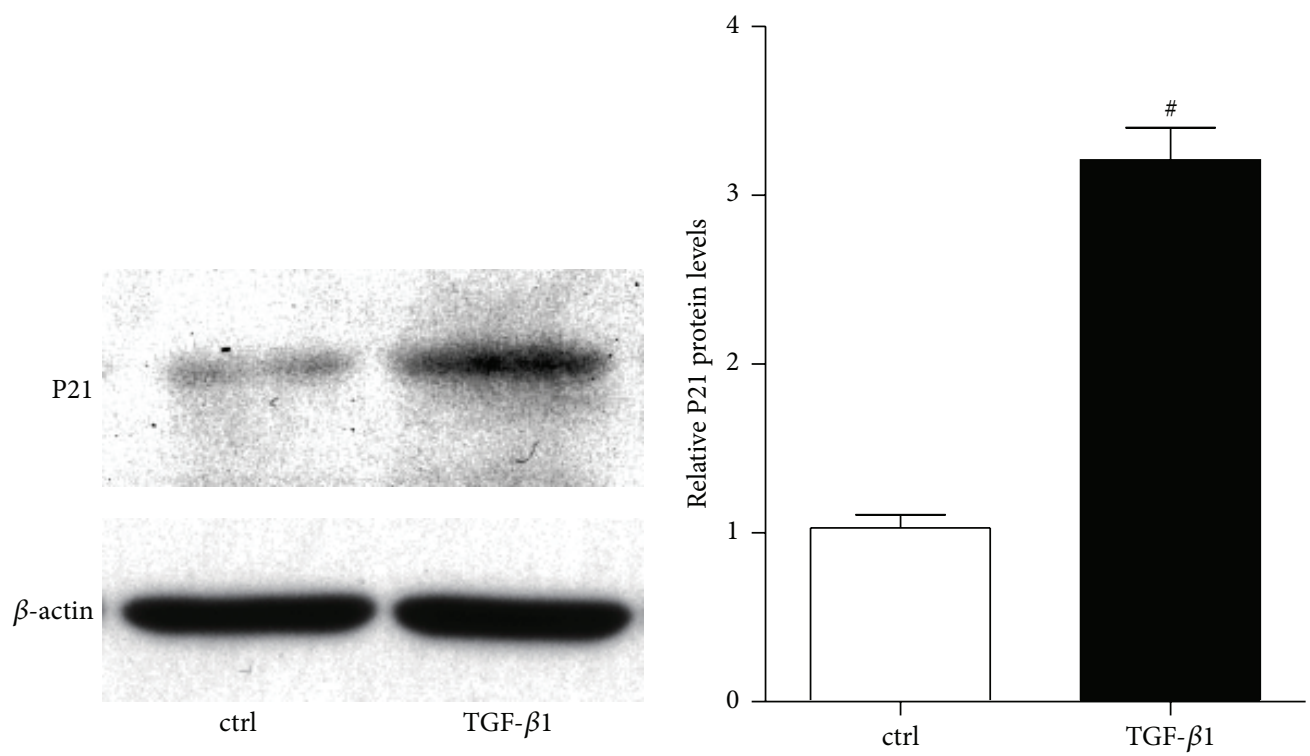

(b)

FIGURE 1: Changes in relative expression of the p21 mRNA and protein between TGF- $\beta 1$ treatment and control (ctrl) groups. TGF- $\beta 1$ treated $\mathrm{MC}$ and control groups are investigated by RT-QPCR (a) and western blot (b); $\beta$-actin was used as internal control gene. Results are expressed as fold over control (mean $\pm \mathrm{SEM} ;{ }^{\#} P<0.05$ versus ctrl, $n=3$ ).

gene expression, RMCs were transfected with $300 \mathrm{ng}$ siRNA oligonucleotides targeting SET7/9 (siSET7/9) or negative control siRNAs (siNeg) and then treated with or without TGF- $\beta 1(10 \mathrm{ng} / \mathrm{mL})$ for $6 \mathrm{~h}$, and mRNA levels were analyzed by RT-QPCR. As shown in Figure 4(b), TGF- $\beta 1$-induced p21 mRNA level was significantly attenuated in siSET7/9 transfection group compared with siNeg group. In contrast, there were no significant changes in CypA mRNA levels induced with or without TGF- $\beta 1$ between siSET7/9 and siNeg groups (Figure 4(b)). These findings further supported the key role of SET7/9 in regulating TGF- $\beta 1$-induced p21 gene expression in RMC.

\section{Discussion}

In the present report, firstly we confirmed that TGF- $\beta 1$ treatment could upregulate p21 gene expression in RMC; then we found significant changes of histone lysine methylations, including $\mathrm{H} 3 \mathrm{~K} 9 \mathrm{me} 2 / 3$ and $\mathrm{H} 3 \mathrm{~K} 4 \mathrm{mel} / 2 / 3$ levels at $\mathrm{p} 21$ gene promoter, which were closely associated with p21 gene expression; further results showed that SET7/9, the specific H3K4mel HMT, was involved in TGF- $\beta 1$ induced p21 gene upregulation in RMC.

It is widely known that CDKI p21 $1^{\text {Cip1/WAF1 }}$ (p21) plays a key role in $\mathrm{MC}$ hypertrophy and glomerular hypertrophy 


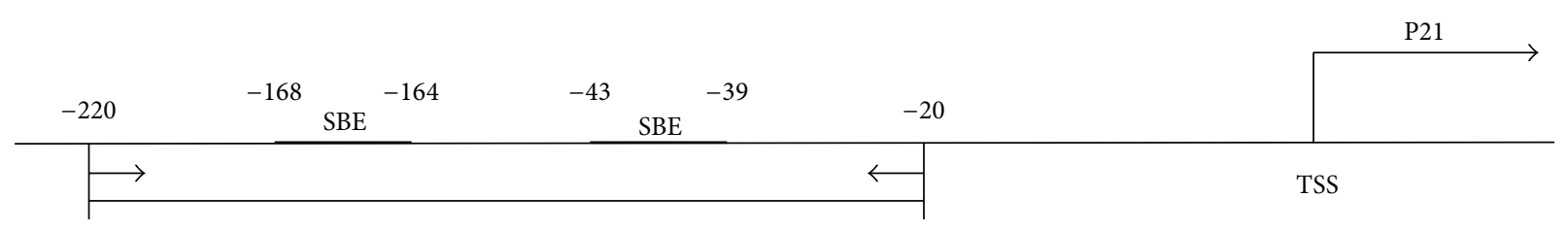

(a)
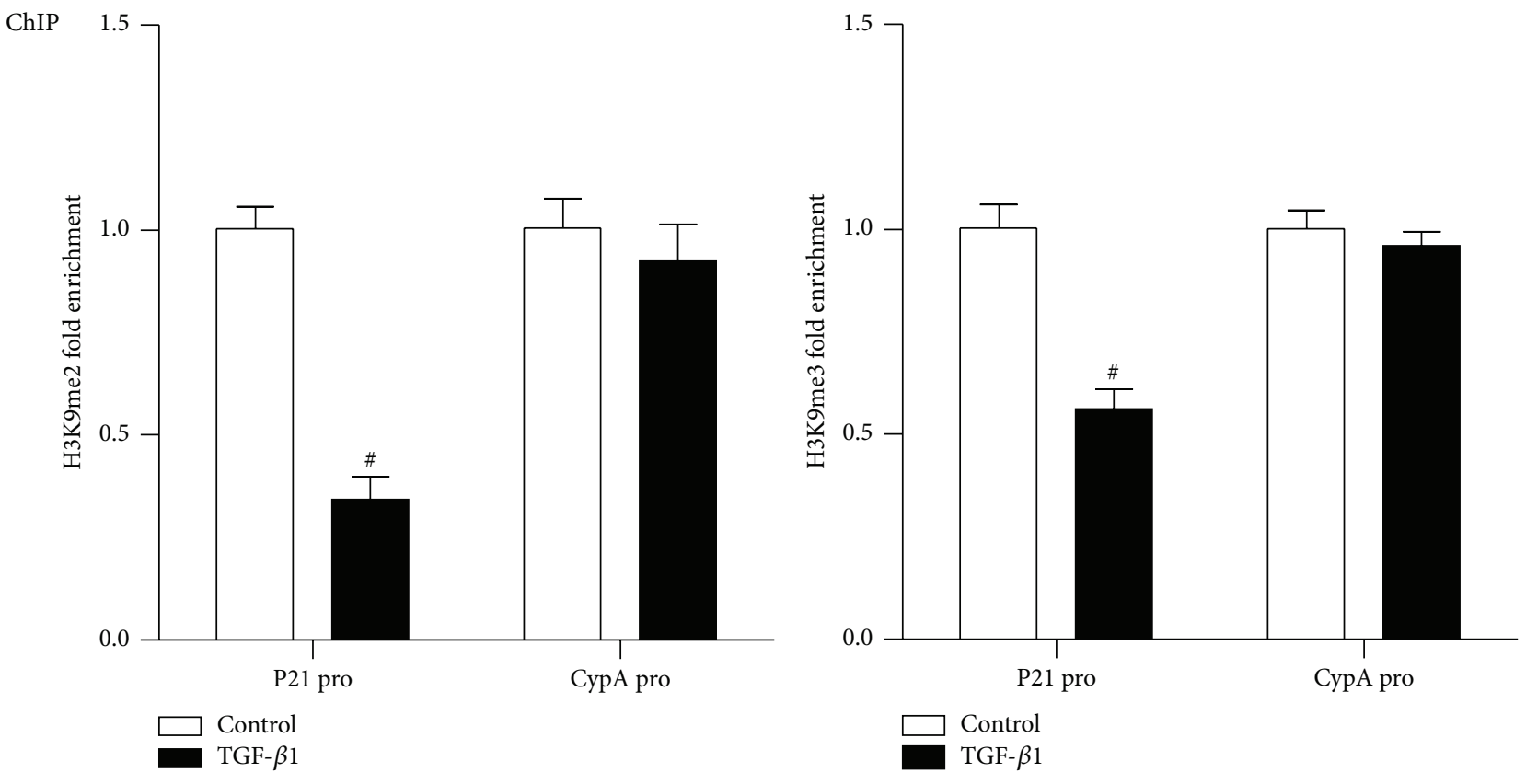

(b)

FIGURE 2: TGF- $\beta 1$ downregulates H3K9me2/3 levels at p21 gene promoter in RMC. (a) Map showing locations of p21 promoter primer used for ChIP-QPCRs. TSS: transcription start site; SBE: Smad binding elements. (b) ChIP assays performed with H3K9me2 and H3K9me3 antibodies normalized to input DNA. Results are expressed as fold over control (mean $\pm \mathrm{SEM} ;{ }^{*} P<0.05$ versus ctrl, $n=3$ ).

leading to chronic renal diseases including $\mathrm{DN}[1,3,4,7,8$, $29,30] ;$ p21 is the target gene of multiple cytokines and growth factors including TGF- $\beta 1[5,8,19]$. However, p21 expression can be modulated through PTM mechanisms [29, 31]. Multiple studies have revealed that the key role of histone PTMs, such as phosphorylation, acetylation, and methylaiton, in gene transcription $[32,33]$. For instance, TGF- $\beta 1$ induced $\mathrm{H} 3 \mathrm{~K} 9 / 14 \mathrm{Ac}$ and acetylation of Smad2/3 playing key roles in p21 gene expression in MC. Howerver, to the best of our knowledge, there is no data about histone lysine methylation and SET7/9 associated mechanism in modulating p21 gene expression.

H3K9me2 and H3K9me3 have been extensively studied and characterized as contributors to transcriptional repression and gene silencing in general $[23,34-36]$. In a previous experiment using cultured vascular smooth muscle cells (VSMCs) from diabetic $\mathrm{db} / \mathrm{db}$ mice, under normal conditions and exposed to TNF- $\alpha$ conditions, led to decreased levels of $\mathrm{H} 3 \mathrm{~K} 9 \mathrm{me} 3$ at key inflammatory genes promoters and inversely correlated with the increased expression of these inflammatory genes [37]. Further study in cultured human VSMCs and endothelial cells showed that exposure to $\mathrm{HG}$ also led to decreased $\mathrm{H} 3 \mathrm{~K} 9 \mathrm{me} 3$ levels, implicating that downregulation of repressive $\mathrm{H} 3 \mathrm{~K} 9 \mathrm{me} 3$ can increase proinflammatory genes expression under diabetic conditions [37, 38]. In addition, data from our previous study suggested that $\mathrm{H} 3 \mathrm{~K} 9 \mathrm{me} 2$ and $\mathrm{H} 3 \mathrm{~K} 9 \mathrm{me} 3$ levels were decreased at ECM associated genes promoters in TGF- $\beta 1$ and HG stimulated RMCs, which were inversely correlated with the increased expression of these profibrotic genes [23]. Similarly to these collective findings, our current results demonstrated that TGF- $\beta 1$ decreased $\mathrm{H} 3 \mathrm{~K} 9 \mathrm{me} 2$ and $\mathrm{H} 3 \mathrm{~K} 9 \mathrm{me} 3$ levels in the promoter of p21 for the first time, which ultimately led to p21 gene upregulation, suggesting that decrease of repressive histone lysine methylation may involve in TGF- $\beta 1$ induced $\mathrm{p} 21$ gene expression.

Increasing evidences showed that histone $\mathrm{H} 3$ lysine 4 methylation (H3K4me) including mono-, di-, and trimethylation enriched at promoter, enhancer, and other regulatory sequences is broadly associated with active genes expression $[34,39-42]$. Our previous results showed that TGF$\beta 1$ induced $\mathrm{H} 3 \mathrm{~K} 4 \mathrm{mel} / 2 / 3$ increases in parallel with the decreases of $\mathrm{H} 3 \mathrm{~K} 9 \mathrm{me} 2 / 3$ at ECM associated genes promoters, suggesting that $\mathrm{H} 3 \mathrm{Kme}$ changes may further cause these genes upregulation [23]. To further understand the key roles of H3K4me in regulating TGF- $\beta 1$-induced p 21 expression, we 

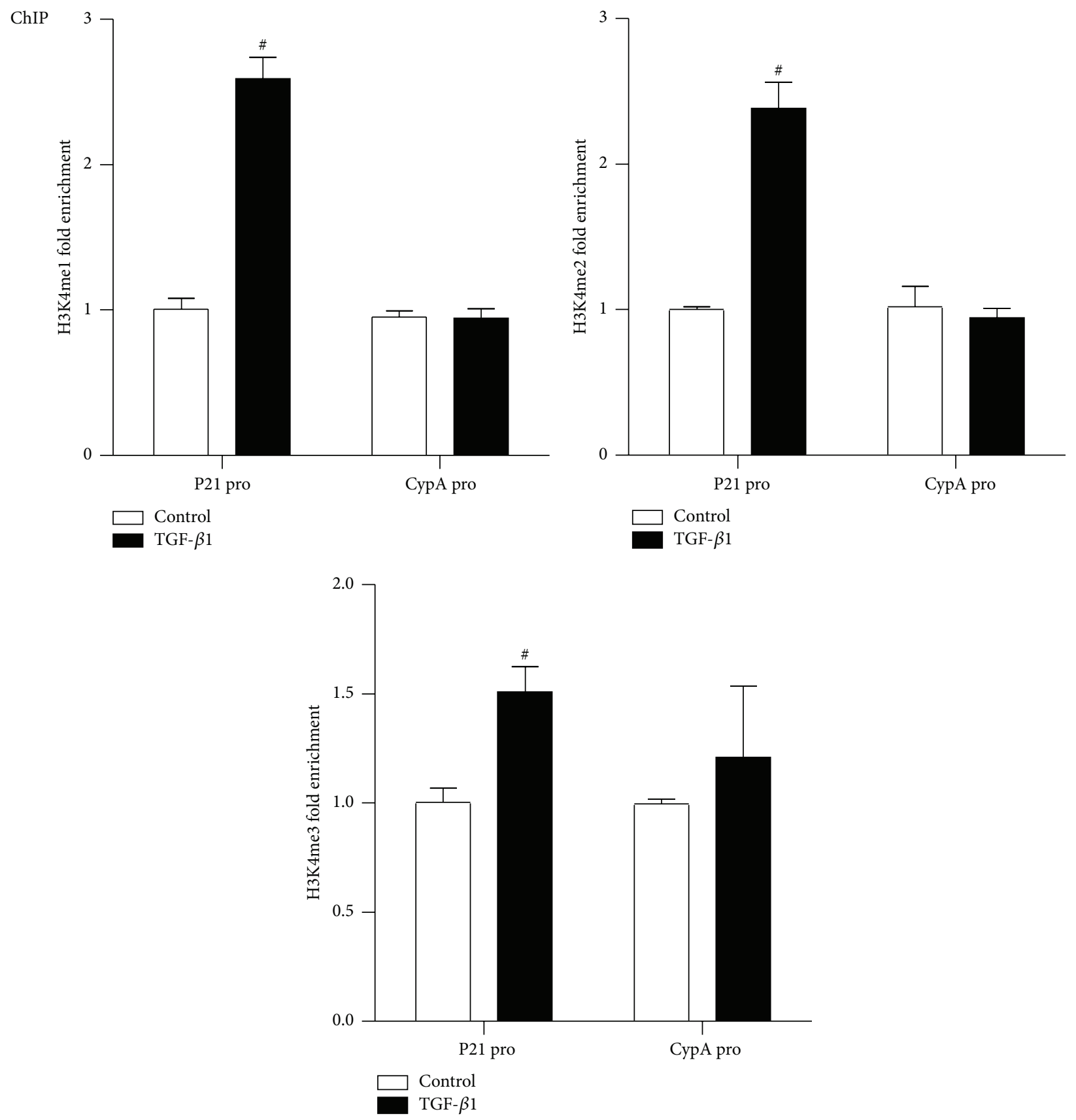

FIGURE 3: TGF- $\beta 1$ increases H3K4me1/2/3 levels at p21 gene promoter in RMC. ChIP assays performed with H3K4mel, H3K4me2, and H3K4me3 antibodies normalized to input DNA. Results are expressed as fold over control (mean \pm SEM; ${ }^{*} P<0.05$ versus ctrl, $n=3$ ).

investigated the levels of $\mathrm{H} 3 \mathrm{~K} 4 \mathrm{mel} / 2 / 3$ in RMC exposed to TGF- $\beta 1$ for $24 \mathrm{~h}$; subsequently our current results showed that TGF- $\beta 1$ upregulated p21 gene expression in RMC, which is positively correlative with the increased $\mathrm{H} 3 \mathrm{~K} 4 \mathrm{mel} / 2 / 3$ levels at the $\mathrm{p} 21$ promoter.

HMT STE7/9 has been demonstrated to not only specially catalyze H3K4mel [26, 43], but also methylate nonhistone proteins such as P53 [44, 45], TAF10 [46], DNMT1 [47], and P65 [48, 49]. SET7/9 was reported to regulate the expression of HG-induced NF- $\kappa$ B subset p65 and inflammatory genes expressions in endothelial cells, which were involved in the "metabolic memory" phenomenon [24]. Similarly, SET7/9 took part in the TNF- $\alpha$-induced target inflammatory genes expressions of NF- $\kappa \mathrm{B}$ pathway in monocytes [25]. A previous study showed that TGF- $\beta 1$ could increase both the expression of SET7/9 and the recruitment of SET7/9 at the ECM associated genes promoters, and knockdown of SET7/9 could specially decrease global H3K4mel level; all the data suggested that SET7/9-mediated H3K4mel was involved in the TGF- $\beta 1$-induced ECM genes upregulation in RMCs. Similarly, in the present study we demonstrated that TGF- $\beta 1$ could increase SET7/9 occupancy at p21 gene 

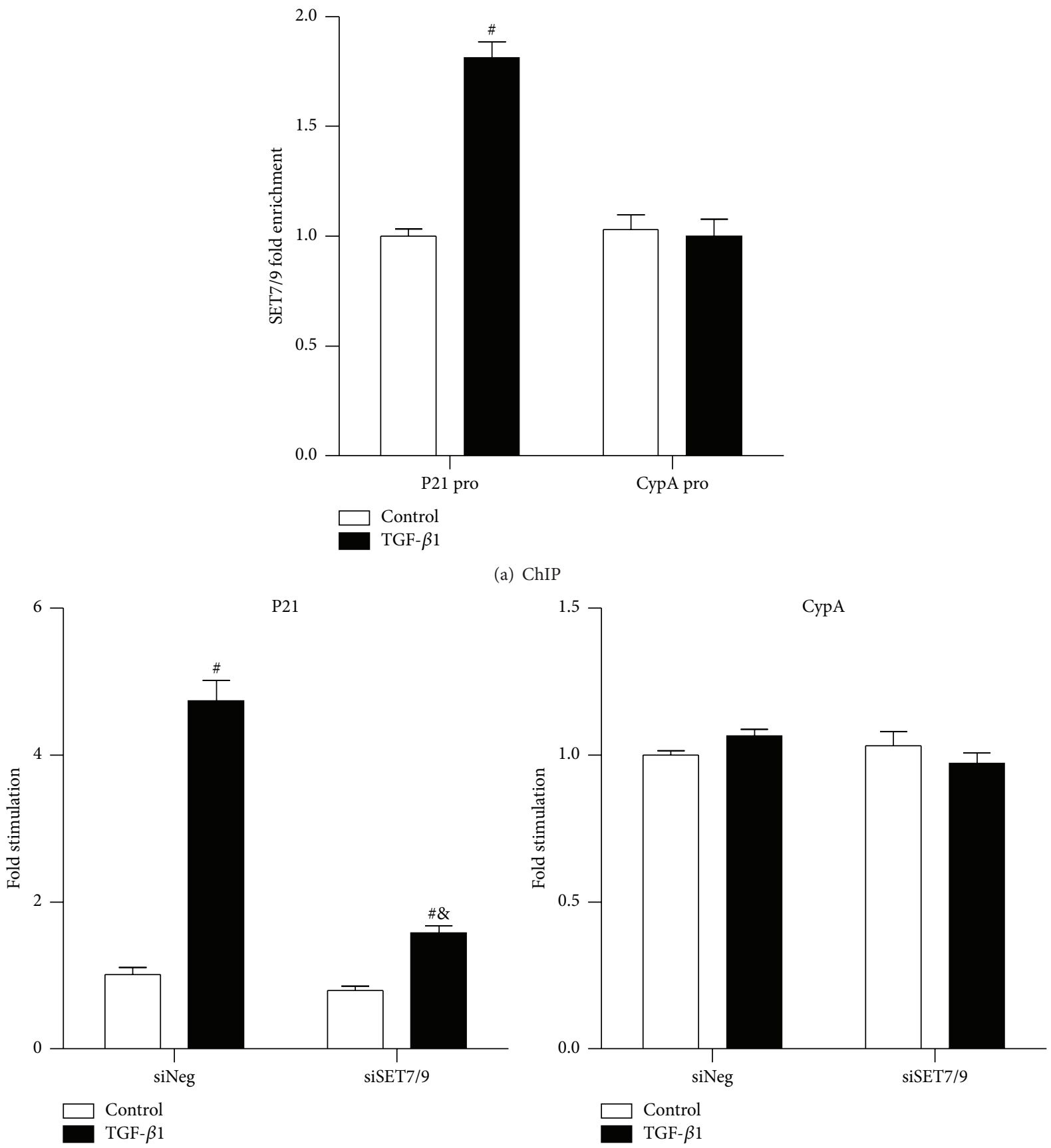

(b) mRNA

FIGURE 4: TGF- $\beta 1$ enhances SET7/9 recruitment at p21 gene promoter and SET7/9 is involved in TGF- $\beta 1$ induced p21 gene expression in RMC. (a) ChIP assays performed with SET7/9 antibody normalized to input DNA. Result was expressed as fold over control (mean \pm SEM; ${ }^{\#} P<0.05$ versus ctrl, $n=3$ ). (b) p21 mRNA expressions are investigated by RT-QPCR; $\beta$-actin was used as internal control gene. Results are expressed as fold over control (mean \pm SEM; ${ }^{\#} P<0.05$ versus ctrl; ${ }^{\circledR} P<0.05$ versus siNeg + TGF- $\beta 1, n=3$ ).

promoter, and silencing SET7/9 with siRNAs could partly abolish TGF- $\beta 1$-induced p21 gene upregulation in RMC, supporting that SET7/9-dependent H3K4mel plays a key role in p21 expression and SET7/9 could be a strong preventive agent against RMC hypertrophy in CKD. Further studies are necessary to reveal cooperative roles of other HMTs mediating $\mathrm{H} 3 \mathrm{~K} 4 \mathrm{me} 2 / 3$ and $\mathrm{H} 3 \mathrm{~K} 9 \mathrm{me} 2 / 3$ in modulating $\mathrm{p} 21$ gene expression in response to TGF- $\beta 1$.
In a recent study in $\mathrm{MC}$ linked to $\mathrm{DN}, \mathrm{TGF}-\beta 1$ has been shown to upregulate $\mathrm{H} 3 \mathrm{~K} 9 / 14 \mathrm{Ac}$ level at p21 promoter and increase $\mathrm{p} 21$ gene expression mediated by HATs including CBP and p300, but not p/CAF [22], and in the present study we demonstrate that TGF- $\beta 1$ can decrease the levels of repressive chromatin histone methylation marks $\mathrm{H} 3 \mathrm{~K} 9 \mathrm{me}$ in RMC, which are associated with the upregulation of p21 expression, suggesting that a cooperative role between active 
and repressive marks at the $\mathrm{K} 9$ site and a crosstalk between HMTs and HATs may control TGF- $\beta 1$-induced p21 expression. Several previous studies have revealed that HDACs are involved in the production of TGF- $\beta 1$ induced ECM and subsequent kidney fibrosis associated with diabetic kidneys $[50,51]$. Further studies are needed to demonstrate such interplay between histone lysine methylation and acetylation and the roles of respective catalytic enzymes in gene expression.

In conclusion, our study provides extensive evidence that TGF- $\beta 1$-induced $\mathrm{p} 21$ gene expression related to MC hypertrophy is correlative with the significant changes in promoter histone $\mathrm{H} 3 \mathrm{~K} 9$ and $\mathrm{H} 3 \mathrm{~K} 4$ methylations in RMCs; HMT SET7/9 plays an important role in the pathogenesis. Therefore, it is possible that histone lysine methylations and HMT SET7/9 could serve as potential therapeutic agents for MC hypertrophy associated CKD including DN.

\section{Competing Interests}

The authors declare that there are no competing interests regarding the publication of this paper.

\section{Acknowledgments}

The authors thank all participants in this work and those who generously provided reagents. This work was supported by grants from the International Cooperation Project of Jilin provincial Science \& Technology (20140414030GH) to Guangdong Sun.

\section{References}

[1] C. B. Marshall and S. J. Shankland, "Cell cycle and glomerular disease: a minireview," Nephron Experimental Nephrology, vol. 102, no. 2, pp. e39-e48, 2006.

[2] G. Wolf, "Cell cycle regulation in diabetic nephropathy," Kidney International, vol. 58, supplement 77, pp. S59-S66, 2000.

[3] L.-Q. Qiu, R. Sinniah, and S. I.-H. Hsu, "Role of differential and cell type-specific expression of cell cycle regulatory proteins in mediating progressive glomerular injury in human $\operatorname{IgA}$ nephropathy," Laboratory Investigation, vol. 84, no. 9, pp. 11121125, 2004.

[4] C.-J. Kuan, M. Al-Douahji, and S. J. Shankland, "The cyclin kinase inhibitor p21WAF1, CIP1 is increased in experimental diabetic nephropathy: potential role in glomerular hypertrophy," Journal of the American Society of Nephrology, vol. 9, no. 6, pp. 986-993, 1998.

[5] T. Monkawa, K. Hiromura, G. Wolf, and S. J. Shankland, “The hypertrophic effect of transforming growth factor- $\beta$ is reduced in the absence of cyclin-dependent kinase-inhibitors p21 and p27," Journal of the American Society of Nephrology, vol. 13, no. 5, pp. 1172-1178, 2002.

[6] S. J. Shankland, "Cell cycle regulatory proteins in glomerular disease," Kidney International, vol. 56, no. 4, pp. 1208-1215, 1999.

[7] S. V. Griffin, R. Pichler, M. Dittrich, R. Durvasula, and S. J. Shankland, "Cell cycle control in glomerular disease," Springer Seminars in Immunopathology, vol. 24, no. 4, pp. 441-457, 2003.

[8] Y.-P. Fan and R. H. Weiss, "Exogenous attenuation of p21(Waf1/ Cip1) decreases mesangial cell hypertrophy as a result of hyperglycemia and IGF-1," Journal of the American Society of Nephrology, vol. 15, no. 3, pp. 575-584, 2004.

[9] M. Al-Douahji, J. Brugarolas, P. A. Brown, C. O. StehmanBreen, C. E. Alpers, and S. J. Shankland, "The cyclin kinase inhibitor p21WAF1/CIP1 is required for glomerular hypertrophy in experimental diabetic nephropathy," Kidney International, vol. 56, no. 5, pp. 1691-1699, 1999.

[10] M. E. Choi, E.-G. Kim, Q. Huang, and B. J. Ballermann, "Rat mesangial cell hypertrophy in response to transforming growth factor- $\beta 1$," Kidney International, vol. 44, no. 5, pp. 948-958, 1993.

[11] L. A. Stephenson, L. B. Haney, I. M. Hussaini, L. R. Karns, and W. F. Glass II, "Regulation of smooth muscle $\alpha$-actin expression and hypertrophy in cultured mesangial cells," Kidney International, vol. 54, no. 4, pp. 1175-1187, 1998.

[12] K. Sharma and F. N. Ziyadeh, "Renal hypertrophy is associated with upregulation of TGF-beta 1 gene expression in diabetic BB rat and NOD mouse," American Journal of Physiology-Renal Physiology, vol. 267, no. 6, part 2, pp. F1094-F1001, 1994.

[13] J. H. Oh, H. Ha, M. R. Yu, and H. B. Lee, "Sequential effects of high glucose on mesangial cell transforming growth factor- $\beta 1$ and fibronectin synthesis," Kidney International, vol. 54, no. 6, pp. 1872-1878, 1998.

[14] K. Fukami, S. Ueda, S.-I. Yamagishi et al., "AGEs activate mesangial TGF- $\beta$-Smad signaling via an angiotensin II type I receptor interaction," Kidney International, vol. 66, no. 6, pp. 2137-2147, 2004.

[15] T. A. McGowan and K. Sharma, "Regulation of inositol 1,4,5-trisphosphate receptors by transforming growth factor$\beta$ : implications for vascular dysfunction in diabetes," Kidney International, vol. 58, supplement 77, pp. S99-S103, 2000.

[16] K. H. Choi, S. W. Kang, H. Y. Lee, and D. S. Han, "The effects of high glucose concentration on angiotensin II- or transforming growth factor- $\beta$-induced DNA synthesis, hypertrophy and collagen synthesis in cultured rat mesangial cells," Yonsei Medical Journal, vol. 37, no. 5, pp. 302-311, 1996.

[17] F. Das, N. Ghosh-Choudhury, A. Bera et al., “Transforming growth factor $\beta$ integrates Smad 3 to mechanistic target of rapamycin complexes to arrest deptor abundance for glomerular mesangial cell hypertrophy," The Journal of Biological Chemistry, vol. 288, no. 11, pp. 7756-7768, 2013.

[18] J. T. Park, M. Kato, H. Yuan et al., "FOG2 protein down-regulation by transforming growth factor- $\beta 1$-induced microRNA$200 \mathrm{~b} / \mathrm{c}$ leads to Akt kinase activation and glomerular mesangial hypertrophy related to diabetic nephropathy," The Journal of Biological Chemistry, vol. 288, no. 31, pp. 22469-22480, 2013.

[19] N. A. Wahab, B. S. Weston, T. Roberts, and R. M. Mason, "Connective tissue growth factor and regulation of the mesangial cell cycle: role in cellular hypertrophy," Journal of the American Society of Nephrology, vol. 13, no. 10, pp. 2437-2445, 2002.

[20] J.-M. Zheng, J.-M. Zhu, L.-S. Li, and Z.-H. Liu, "Rhein reverses the diabetic phenotype of mesangial cells over-expressing the glucose transporter (GLUT1) by inhibiting the hexosamine pathway," British Journal of Pharmacology, vol. 153, no. 7, pp. 1456-1464, 2008.

[21] H. Zheng, S. A. Whitman, W. Wu et al., "Therapeutic potential of Nrf2 activators in streptozotocin-induced diabetic nephropathy," Diabetes, vol. 60, no. 11, pp. 3055-3066, 2011.

[22] H. Yuan, M. A. Reddy, G. Sun et al., "Involvement of p300/ CBP and epigenetic histone acetylation in TGF- $\beta 1$-mediated gene transcription in mesangial cells," American Journal of Physiology-Renal Physiology, vol. 304, no. 5, pp. F601-F613, 2013. 
[23] G. Sun, M. A. Reddy, H. Yuan, L. Lanting, M. Kato, and R. Natarajan, "Epigenetic histone methylation modulates fibrotic gene expression," Journal of the American Society of Nephrology, vol. 21, no. 12, pp. 2069-2080, 2010.

[24] A. El-Osta, D. Brasacchio, D. Yao et al., "Transient high glucose causes persistent epigenetic changes and altered gene expression during subsequent normoglycemia," Journal of Experimental Medicine, vol. 205, no. 10, pp. 2409-2417, 2008.

[25] Y. Li, M. A. Reddy, F. Miao et al., "Role of the histone H3 lysine 4 methyltransferase, SET7/9, in the regulation of NF$\kappa \mathrm{B}$-dependent inflammatory genes: relevance to diabetes and inflammation," The Journal of Biological Chemistry, vol. 283, no. 39, pp. 26771-26781, 2008.

[26] J. Chen, Y. Guo, W. Zeng et al., "ER stress triggers MCP-1 expression through SET7/9-induced histone methylation in the kidneys of $\mathrm{db} / \mathrm{db}$ mice," American Journal of Physiology - Renal Physiology, vol. 306, no. 8, pp. F916-F925, 2014.

[27] M. Mishra, Q. Zhong, and R. A. Kowluru, "Epigenetic modifications of Keapl regulate its interaction with the protective factor Nrf2 in the development of diabetic retinopathy," Investigative Ophthalmology \& Visual Science, vol. 55, no. 11, pp. 7256-7265, 2014.

[28] K. Sasaki, S. Doi, A. Nakashima et al., "Inhibition of SET domain-containing lysine methyltransferase 7/9 ameliorates renal fibrosis," Journal of the American Society of Nephrology, vol. 27, no. 1, pp. 203-215, 2015.

[29] S. J. Shankland and G. Wolf, "Cell cycle regulatory proteins in renal disease: role in hypertrophy, proliferation, and apoptosis," American journal of physiology-Renal physiology, vol. 278, no. 4, pp. F515-F529, 2000.

[30] L. Mahimainathan, F. Das, B. Venkatesan, and G. G. Choudhury, "Mesangial cell hypertrophy by high glucose is mediated by downregulation of the tumor suppressor PTEN," Diabetes, vol. 55, no. 7, pp. 2115-2125, 2006.

[31] M. Akashi, Y. Osawa, H. P. Koeffler, and M. Hachiya, "p21WAF1 expression by an activator of protein kinase $\mathrm{C}$ is regulated mainly at the post-transcriptional level in cells lacking p53: important role of RNA stabilization," Biochemical Journal, vol. 337, no. 3, pp. 607-616, 1999.

[32] S. R. Bhaumik, E. Smith, and A. Shilatifard, "Covalent modifications of histones during development and disease pathogenesis," Nature Structural and Molecular Biology, vol. 14, no. 11, pp. 10081016, 2007.

[33] T. Kouzarides, "Chromatin modifications and their function," Cell, vol. 128, no. 4, pp. 693-705, 2007.

[34] C. Martin and Y. Zhang, "The diverse functions of histone lysine methylation," Nature Reviews Molecular Cell Biology, vol. 6, no. 11, pp. 838-849, 2005.

[35] P. Völkel and P.-O. Angrand, "The control of histone lysine methylation in epigenetic regulation," Biochimie, vol. 89 , no. 1 , pp. 1-20, 2007.

[36] Y. Kera, Y. Katoh, M. Ohta, M. Matsumoto, T. TakanoYamamoto, and K. Igarashi, "Methionine adenosyltransferase II-dependent histone H3K9 methylation at the COX-2 gene locus," The Journal of Biological Chemistry, vol. 288, no. 19, pp. 13592-13601, 2013.

[37] L. M. Villeneuve, M. A. Reddy, L. L. Lanting, M. Wang, L. Meng, and R. Natarajan, "Epigenetic histone H3 lysine 9 methylation in metabolic memory and inflammatory phenotype of vascular smooth muscle cells in diabetes," Proceedings of the National Academy of Sciences of the United States of America, vol. 105, no. 26, pp. 9047-9052, 2008.
[38] D. Brasacchio, J. Okabe, C. Tikellis et al., "Hyperglycemia induces a dynamic cooperativity of histone methylase and demethylase enzymes associated with gene-activating epigenetic marks that coexist on the lysine tail," Diabetes, vol. 58, no. 5, pp. 1229-1236, 2009.

[39] E. Shen, H. Shulha, Z. Weng, and S. Akbarian, "Regulation of histone H3K4 methylation in brain development and disease," Philosophical Transactions of the Royal Society B: Biological Sciences, vol. 369, no. 1652, 2014.

[40] T. Jenuwein and C. D. Allis, "Translating the histone code," Science, vol. 293, no. 5532, pp. 1074-1080, 2001.

[41] A. J. Ruthenburg, C. D. Allis, and J. Wysocka, "Methylation of lysine 4 on histone $\mathrm{H} 3$ : intricacy of writing and reading a single epigenetic mark," Molecular Cell, vol. 25, no. 1, pp. 15-30, 2007.

[42] M. Hampsey and D. Reinberg, "Tails of intrigue: phosphorylation of RNA polymerase II mediates histone methylation," Cell, vol. 113, no. 4, pp. 429-432, 2003.

[43] P. Hu and Y. Zhang, "Catalytic mechanism and product specificity of the histone lysine methyltransferase SET7/9: an ab initio QM/MM-FE study with multiple initial structures," Journal of the American Chemical Society, vol. 128, no. 4, pp. 1272-1278, 2006.

[44] S. Chuikov, J. K. Kurash, J. R. Wilson et al., "Regulation of p53 activity through lysine methylation," Nature, vol. 432, no. 7015, pp. 353-360, 2004.

[45] S. L. Berger, "The complex language of chromatin regulation during transcription," Nature, vol. 447, no. 7143, pp. 407-412, 2007.

[46] A. Kouskouti, E. Scheer, A. Staub, L. Tora, and I. Talianidis, "Gene-specific modulation of TAF10 function by SET9mediated methylation," Molecular Cell, vol. 14, no. 2, pp. 175182, 2004.

[47] P.-O. Estève, H. G. Chin, J. Benner et al., "Regulation of DNMT1 stability through SET7-mediated lysine methylation in mammalian cells," Proceedings of the National Academy of Sciences of the United States of America, vol. 106, no. 13, pp. 50765081, 2009.

[48] C.-K. Ea and D. Baltimore, "Regulation of NF- $\kappa$ B activity through lysine monomethylation of p65," Proceedings of the National Academy of Sciences of the United States of America, vol. 106, no. 45, pp. 18972-18977, 2009.

[49] X.-D. Yang, B. Huang, M. Li, A. Lamb, N. L. Kelleher, and L.-F. Chen, "Negative regulation of NF- $\kappa$ B action by Set9-mediated lysine methylation of the relA subunit," The EMBO Journal, vol. 28, no. 8, pp. 1055-1066, 2009.

[50] H. Noh, Y. O. Eun, Y. S. Ji et al., "Histone deacetylase-2 is a key regulator of diabetes- and transforming growth factor- $\beta 1$ induced renal injury," American Journal of Physiology-Renal Physiology, vol. 297, no. 3, pp. F729-F738, 2009.

[51] M. Yoshikawa, K. Hishikawa, T. Marumo, and T. Fujita, "Inhibition of histone deacetylase activity suppresses epithelial-tomesenchymal transition induced by TGF- $\beta 1$ in human renal epithelial cells," Journal of the American Society of Nephrology, vol. 18, no. 1, pp. 58-65, 2007. 


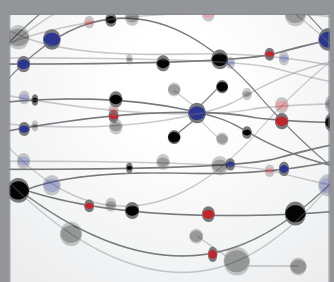

The Scientific World Journal
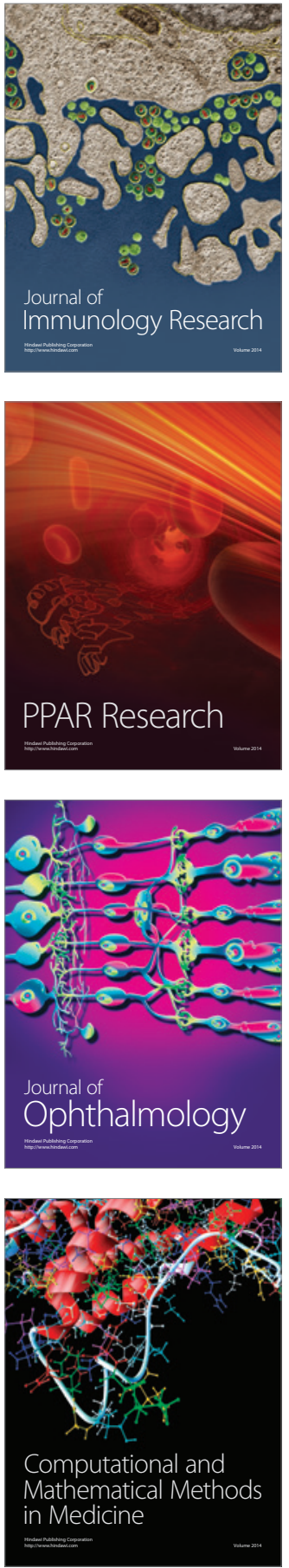

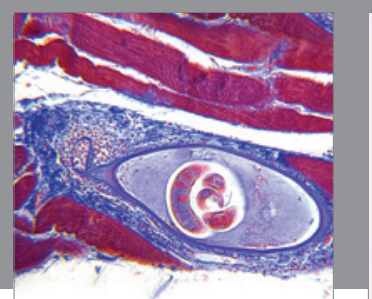

Gastroenterology Research and Practice

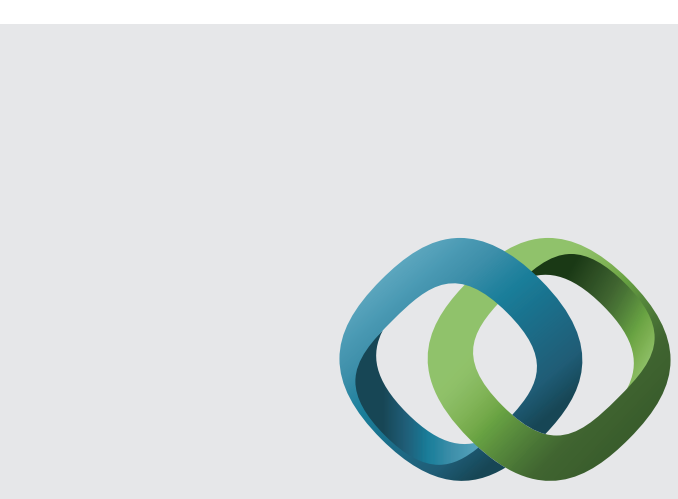

\section{Hindawi}

Submit your manuscripts at

http://www.hindawi.com
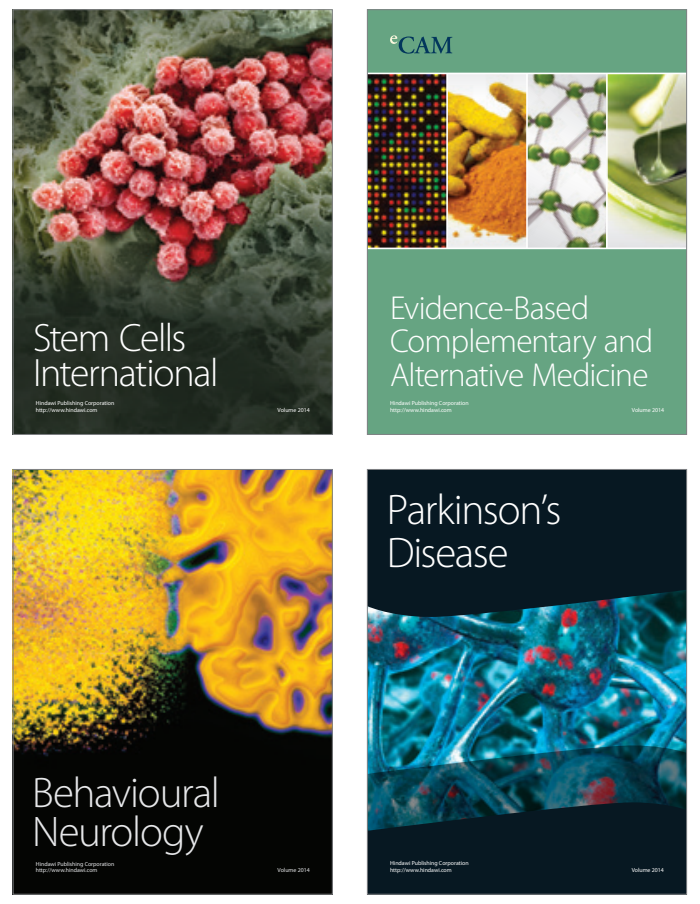
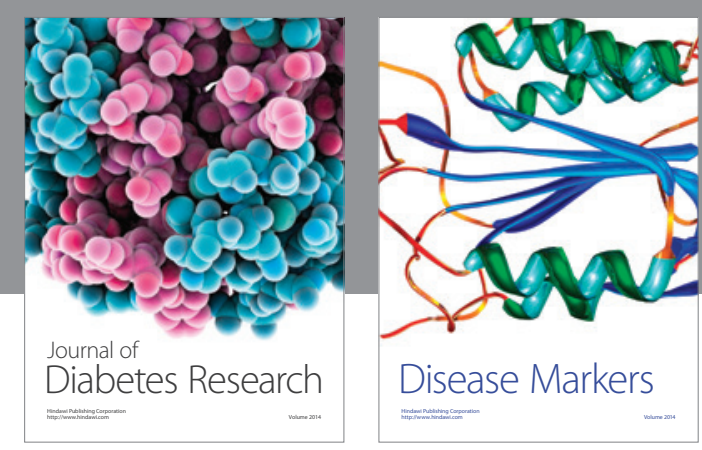

Disease Markers
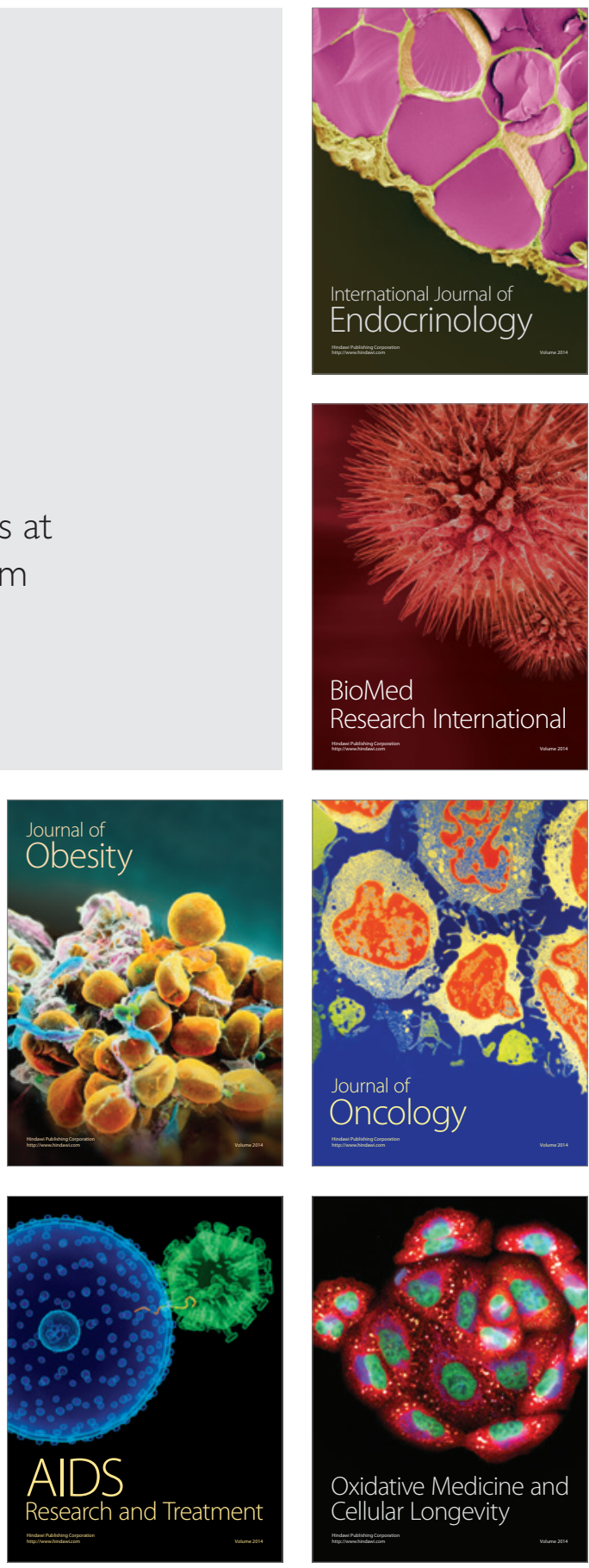